\title{
Analyzing key influence factors of city logistics development using the fuzzy decision making trial and evaluation laboratory (DEMATEL) method
}

\author{
Hongmei $\mathrm{He}^{\star}$ and Haifang Cheng \\ School of Management, Huazhong University of Science and Technology, 1037, Luoyu Road, Wuhan, Hubei, China,
} 430074.

Accepted 15 June, 2012

As the urban sprawl, the influence of city logistics on economy, society and environment is more and more remarkable, so city logistics receives increasingly attention recently. Since the city logistics system is a complex system affected by many factors, and these factors affect each other, it is difficult to improve all the influence factors at the same time to enhance the performance of city logistics. Therefore, there is need to find out the key influence factors of city logistics in order to improve them gradually. Considering the vagueness of human judgments, this paper pioneers in exploring the decision-making trial and evaluation laboratory (DEMATEL) method combining with fuzzy logic to identify the key influence factors of city logistics. According to analysis results, six key influence factors are identified, which are helpful to propose a comprehensive measure. As the implementation of this comprehensive measure, all other factors can be improved step by step. Finally the development level of city logistics might be improved.

Key words: City logistics, Key factor, fuzzy logic, decision-making trial and evaluation laboratory (DEMATEL) method

\section{INTRODUCTION}

City is the commodity's consumption center, distribution center and production center. Activities in these centers are inseparable from urban freight transportation. However, urban freight transportation also brings much negative impact, such as traffic congestion, environment pollution and energy consumption, etc, which need a comprehensive solution. One such feasible measure is to develop city logistics. As a general approach, city logistics could reduce the adverse impact brought by urban freight transportation. Simultaneously, the promotion of city logistics to economy can not be neglected. Thus, development of city logistics can not only enhance the development of urban economy, perfect the function of city, reduce the negative impact on environment, but also

*Corresponding author. E-mail: hehongmei321@126.com. Tel: +8613397153667. can promote the comprehensive competitiveness of the city.

In order to make full use of city logistics' advantages, it is necessary to take some city logistics measures. Munuzuri et al. (2005) propose lots of specific solutions implemented by local administrations in order to improve urban logistics, such as solutions related to public infrastructure, land use management, access conditions, traffic management, enforcement and promotion. Taniguchi and Tamagawa (2005) take tolling of urban expressways as a city logistics measure, then test a methodology to evaluate this measure considering the behavior of several stakeholders about urban freight transport. Anderson et al. (2005) study a project considering four policy measures (low emission zones, congestion charging, vehicle weight restrictions and vehicle access time restrictions) to meet the urban sustainability objectives. Figliozzi (2011) studies a case in Portland and results that limit travel speeds or increase 
speed limits can reduce $\mathrm{CO}_{2}$ emissions. However, city logistics is a very complex system affected by many factors. In addition these factors have complicated links between each other. So it is difficult to implement specific measures to achieve the improvement of city logistics. Hence, it is necessary to study these influence factors from a systematic angle and identify key influence factors. Then, a comprehensive measure related to key influence factors could be proposed to improve the development level of city logistics.

This paper classifies the influence factors into cause factors group and effect factors group, using the decision-making trial and evaluation laboratory (DEMATEL) method, and it analyzes the impact of two group factors on city logistics respectively, in order to identify key influence factors. However, some influence factors need quantitatively description, but some need qualitative description. People's judgment on qualitative concept is uncertain. Fuzzy logic supplies the solution to uncertainty in this kind of complex system. Therefore, this paper combines DEMATEL method with fuzzy logic to analyze key influence factors of city logistics. Through implementing improvement measures concerning key influence factors, the development level of city logistics can be improved.

The rest of this paper is arranged as follows; review of related literature of city logistics and influence factors; presentation of the principle of fuzzy decision-making trial and evaluation laboratory (DEMATEL) method; analyses of the influence factors of city logistics using proposed method, and acquires key influence factors through analysis of the fuzzy DEMATEL method's results; conclusions and future study.

\section{LITERATURE REVIEW OF CITY LOGISTICS}

\section{City logistics}

In recent years, many problems arise in urban transportation, such as traffic congestion, environment pollution, noise pollution, and so on. To deal with these issues, the concept of city logistics came into being. The aim of city logistics is to improve the efficiency of urban freight transport system, meanwhile reduce its adverse impact.

According to Taniguchi et al. (1999), city logistics are defined as "...the process for totally optimizing the logistics and transport activities by private companies with the support of advanced information systems in urban areas considering the traffic environment, its congestion, safety and energy savings within the framework of a market economy". However, nowadays not only private enterprises play an important role in the development of city logistics, but also the governments promote the improvement of city logistics remarkably. For instance, the application of cooperative transport systems indicates governments collaborate with private companies in order to achieve the aims of city logistics. In some countries, such as Japan and the Netherlands, public authorities supply more support in the development of city logistics.

As seen from the definition, city logistics are a complex system, which not only refers to many stakeholders, such as governments, carriers, shippers, citizens, etc, but also has many influence factors. Even so, some scholars have studied this complicated system. Petersen (2006) presents a method of the future workshop in a kick-off seminar aiming at initiating the development of a business concept for city logistics. Sheu (2006) adopts a dynamic customer group-based logistics resource allocation methodology to study demand-responsive city logistics distribution operations, which reduces the aggregate operational costs and average lead time. Though distribution operation is an important part of city logistics, transportation system is also very critical. Woudsma et al. (2008) apply a spatial-temporal approach to research transportation system performance from the perspective of logistics land use. Carriers or rather logistics service providers also play an important role in city logistics system. Busse (2010) studies the relation between innovation activities and performance of logistics service providers through second data analysis. Taniguchi et al. (2010) connects human security engineering with city logistics to study incorporating risks caused by natural and manmade hazards in city logistics.

Throughout the existing research, most people study the specific part of city logistics, such as freight transport (Anderson et al., 2005; Eduardo and Romero, 2010; Magalhaes, 2010), modeling the vehicle routing and scheduling of pickup/delivery trucks (Taniguchi, 2000, 2001; Tamagawa et al., 2010), city logistics planning (Kuse et al., 2010), the benefit between the public and private sectors (Taniguchi et al., 2003) etc. Researching city logistics from a comprehensive view is very few. So it is essential to study city logistics from the perspective of the whole system and the factors influencing its performance need to be pointed out.

\section{Influence factors}

City logistics system consists of many subsystems. Each subsystem is affected by a large number of factors. So there are a great many factors influencing the performance of the whole city logistics system. With respect to influence factors of city logistics, some scholars do related research from differernt point of view as follows:

1) Taniguchi (2000) proposes five city logistics initiatives, including advanced information system, cooperative freight transport systems, public logistics terminals, load factor controls and underground freight transport systems, which are very effective to improve city logistics. 
2) Considering the interest of urban communities, Munuzuri et al. (2005) classify urban freight solutions into four aspects: public infrastructure, land use management, access conditions and traffic management.

3) BESTUFS (2007) points out three primary classes of measures: goods vehicles access and loading approaches in urban areas (for example, efficient usage of infrastructure, guidance on measures for goods vehicle access and loading in urban areas, technology in urban freight), principal issues involved in last mile solutions (for example, home shopping via e-commerce) and principal issues associated with urban distribution centers.

4) Shao et al. (2009) propose twelve primary criteria to evaluate the competitiveness of city logistics and identify the key factors influencing development of regional logistics through the method of hierarchy analysis thought and fuzzy decision-making principles. The proposed criteria are economic situation, the logistics volume, the logistics industry practitioners, the logistics facilities and equipments, the logistics industry cost, postal communications status, foreign investment, the standard of education, science and technology, trade status, information status, geographical situation and industrial policy environment.

5) Kuse et al. (2010) underline the importance of logistics infrastructure in an effective city logistics system, which contains facility, technology and institutional infrastructures. Facility infrastructure includes physical aspects (for example, transport route networks and logistics facilities) and software aspects (for example, traffic management and control). Technology infrastructure relates to human resources, information infrastructure and industrial resources. Institutional infrastructure refers to social rules together with social consensus that support them.

6) Considering urban goods movements and its actors, Russo and Comi (2010) classify the main city logistics measures into four categories. The first species is measures related to material infrastructure, such as transportation sub-network used only by freight vehicles or urban distribution centers. The second species is measures related to immaterial infrastructure, such as intelligent transportation system (ITS). The third species is measures related to equipment, including new standards for loading units and environmental-friendly vehicles. The last species is measure related to governance, such as traffic regulations.

7) Tamagawa et al. (2010) compare the influence of two measures (road pricing, road pricing and changes of the motorway toll) on stakeholders associated with urban freight transport.

In all these researches, many measures have been proposed from several different perspectives, which are also the important factors impacting the performance of city logistics, but factors that could evaluate the level of logistics service have not been studied. Logistics service level is a significant part of city logistics. The service quality not only concerns the benefit of residents closely, but also influences the general level of city logistics. In this paper, five factors are put forward to evaluate city logistics service level, such as on-time deliveries, logistics cost, the rate of goods defect, customer satisfaction and the reliability of transportation.

On the basis of previous studies, we assess the development of city logistics from four aspects, namely logistics infrastructure, environmental effects, governance measures and logistic service level. Table 1 shows the specific influence factors for city logistics development.

\section{THE FUZZY DEMATEL METHOD}

In a complex system, especially under uncertain environment, the factors in the system directly or indirectly influence each other. Thus, it is very difficult for the decision makers to make decisions from a single factor. If you do not consider this vagueness, the result can be misleading. Exactly, the DEMATEL method can translate the intricate relationships among factors in a complex system into intelligible structure model, and then identify the key factors. Considering the fuzziness of human's judgment, this paper combines DEMATEL method with fuzzy set theory to analyze key influence factors of city logistics. The related content of DEMATEL method and fuzzy logic is presented below.

\section{The DEMATEL method}

The DEMATEL method, originating from the Geneva Research Centre of the Battelle Memorial Institute (Fontela and Gabus, 1976; Gabus and Fontela, 1973), is aimed to solve the complex and difficult problems in the real world. More specifically, it searches for integrated solutions to fragmented and antagonistic problems (Chang et al., 2011). As an analysis method of systematic elements, the DEMATEL method is established on graph theory and matrix tools. Through analyzing logical relationship and direct impact relations between systematic elements, these elements are divided into effected group and causal group. Its obvious advantage is the comprehensive inclusion of several experts' ideas in a certain industry and analysis of complicated relations between systematic elements applying visualization structure model.

Recently, the DEMATEL method has become very popular in Japan, because it is able to pragmatically visualize the structure of complicated causal relationship. Moreover, many scholars use the DEMATEL method to solve systematic problems in many fields of other countries. Tzeng et al. (2007) propose a new method combining factor analysis with DEMATEL method to evaluate e-learning effectiveness, and the rationality of this method is proved through an empirical example of Masterlink Securities Corporation e-learning training programs. Seyed-Hosseini et al. (2006) propose DEMATEL method as an effective methodology to make corrective actions for reprioritization of failure modes in a system, and two real world examples are introduced for verification of DEMATEL method. Nowadays because of the vagueness of human judgment, the majority of scholars combine DEMATEL method with fuzzy set theory to solve the complex system problems. Wu and Lee (2007) take a high-tech company as an example, combining DEMATEL method with fuzzy logic to segment a set of competencies into the cause group and the effect group in order to find out critical criteria 
Table 1. The influence factors of city logistics development.

\begin{tabular}{|c|c|}
\hline Influence aspects & Specific factors \\
\hline \multirow{7}{*}{ Logistics infrastructure } & Transport route networks (S1) \\
\hline & Use of train or underground system (S2) \\
\hline & Use of ship terminals (S3) \\
\hline & Logistics centers (S4) \\
\hline & Hub for air freight (S5) \\
\hline & Human resources (S6) \\
\hline & Information and communications infrastructure (S7) \\
\hline \multirow{4}{*}{ Environmental effects } & Fuel consumed (S8) \\
\hline & Pollutant emissions (S9) \\
\hline & Freight-vehicle related accidents (S10) \\
\hline & Traffic congestion (S11) \\
\hline \multirow{5}{*}{ Governance measures } & Road pricing (S12) \\
\hline & Load factor controls (S13) \\
\hline & Access time windows (S14) \\
\hline & Access according to weight and volume (S15) \\
\hline & Noise regulations (S16) \\
\hline \multirow{5}{*}{ Logistic service level } & On-time deliveries (S17) \\
\hline & Logistics cost (S18) \\
\hline & The rate of goods defect (S19) \\
\hline & Customer satisfaction (S20) \\
\hline & The reliability of transportation (S21) \\
\hline
\end{tabular}

to enrich the required competencies for global managers. Chang et al. (2011) believe that supplier selection has great impact on supply chain management in many corporations, so they analyze the influence factors for supplier selection in the electronic industry using fuzzy DEMATEL method, and draw a conclusion that stable delivery of goods is the key influence factor. Zhou et al. (2011) use the fuzzy DEMATEL method to analyze 20 influence factors of emergency management and finally identify 5 critical success factors. However, this effective DEMATEL method has not been used in the area of city logistics. Consequently, this paper adopts DEMATEL method to analyze influence factors of city logistics, and to find out the key factors in order to improve the development of city logistics gradually.

The procedure of DEMATEL method is presented as follows:

Step 1: Analyze system elements. Collect related information to find out influence factors of the system. Suppose the system contains a set of elements $S=\left\{s_{1}, s_{2}, \cdots, s_{n}\right\}$.

Step 2: Generate the initial direct-relation matrix. In respect of a system containing $n$ factors, apply the matrix $X=\left(x_{i j}\right)_{n \times n}$ to express the degree of direct relation between systematic elements. That $n \times n$ matrix is obtained by pair-wise comparisons in direct influence between elements from a number of experts. $x_{i j}$ indicates the degree that element $S_{i}$ affects element $S_{j}$ directly. If $i=j$, the value of $x_{i j}$ is equal to zero. Namely, the values of all principal diagonal elements $x_{i i}$ in matrix $X$ are equal to zero.

Step 3: Acquire the normalized initial direct-relation matrix. Normalize the initial direct-relation matrix $X$, then the normalized direct-relation matrix $M$ is obtained through Equation 1.

$M=X / \max _{1 \leq i \leq n} \sum_{j=1}^{n} x_{i j}$

Step 4: Determine the total-relation matrix. In order to analyze the indirect effects between systematic factors, it is necessary to determine the total-relation matrix $T$ through Equation 2, where $t_{i j}$ means the degree that element $s_{i}$ has indirect impact on element $S_{j}$ and $I$ is the identity matrix.

$T=\left(t_{i j}\right)_{n \times n}=M(I-M)^{-1}$

Step 5: Calculate the sum of rows and the sum of columns of matrix $T$. The sum of row $i$ is denoted as $R_{i}$, which describes all direct and indirect effect that factor $S_{i}$ gives to all other factors. So $R_{i}$ can be called the degree of influential impact. In the same way, the sum of column $j$ is denoted as $C_{j}$, which presents all direct 
and indirect influence received by factor $j$ from all other factors.

$R_{i}$ and $C_{j}$ can be acquired through Equations 3 and 4 respectively.

$$
\begin{aligned}
& R_{i}=\sum_{j=1}^{n} t_{i j}, i=1,2, \cdots, n \\
& C_{j}=\sum_{i=1}^{n} t_{i j}, j=1,2, \cdots, n
\end{aligned}
$$

Step 6: Calculate the sum and difference of $R_{i}$ and $C_{i}$, then draw the cause-effect graph through the dataset of $\left(R_{i}+C_{i}, R_{i}-C_{i}\right)$. $R_{i}+C_{i}$ means factor $S_{i}$ 's impact on the whole system and other systematic factors' impact on factor $s_{i}$. Thus $R_{i}+C_{i}$ can present the degree of importance that factor $s_{i}$ plays in the whole system. That is the reason why $R_{i}+C_{i}$ is called centrad. Oppositely, $R_{i}-C_{i}$ indicates the net impact that factor $s_{i}$ has on the system.

In the cause-effect relationship diagram, the horizontal axis $R_{i}+C_{i}$ named "Prominence" is made by adding $C_{i}$ to $R_{i}$, and the vertical axis $R_{i}-C_{i}$ named "Relation" is made by subtracting $C_{i}$ from $R_{i}$. The horizontal axis "Prominence" shows the importance of the criterion, whereas the vertical axis "Relation" may classify the factors into the cause group and effect group. If the value of $R_{i}-C_{i}$ is positive, factor $s_{i}$ belongs to the cause group, which has net causal impact on the system. Similarly, if the value of $R_{i}-C_{i}$ is negative, factor $S_{i}$ belongs to the effect group, which is a net result. Therefor the cause-effect relationship diagram constructs a visible structural model effectively to visualize the complicated causal relationships between criteria. Thus it provides an effective method to solve the complex problem.

\section{The fuzzy logic}

In a real world, people often make judgment according to their experience and expertise. Since the practical things are complicated and uncertain to some extent, plus human thought concerning complex things is vague, these make the subjective judgment dubious, namely fuzziness. Especially in various decision-making problems, the fuzziness and vagueness are inherent characteristics; therefore a proper decision-making approach should be capable of dealing with vagueness and ambiguity. To deal with the vagueness of human thought about an intricate or dubious system, Zadeh (1975) first put forward the fuzzy set theory, which provides an approximate and effective means of describing the behavior of too complicated or ill-defined system to admit the precise mathematical analysis through the use of linguistic variables and fuzzy algorithms (Zadeh, 1973).

Since triangular fuzzy numbers are considered as useful means of quantifying the uncertainty in a complex system due to their intuitive and computation-efficient representation (Karsak and Tolga, 2001), they can connect the linguistic variables with fuzzy numbers closely. This paper adopts triangular fuzzy number to link linguistic judgment of experts with triangular fuzzy number correspondingly in Table 2. A triangular fuzzy number can be denoted as $(a, b, c)$, where $a \leq b \leq c$ and $a>0$.The membership function $\mu_{A}(x)$ is defined as follow (Zimmermann, 1991).

$\mu_{A}(x)=\left\{\begin{array}{l}(x-a) /(b-a), a \leq x \leq b, \\ (x-c) /(b-c), b \leq x \leq c, \\ 0, \text { otherwise }\end{array}\right.$

In order to integrate all the experts' judgments effectively, it is necessary to make algebraic operation between triangular fuzzy numbers. For example, $B_{1}=\left(a_{1}, b_{1}, c_{1}\right)$,

$B_{2}=\left(a_{2}, b_{2}, c_{2}\right)$, according to Zadeh (1965), algebraic operation between $B_{1}$ and $B_{2}$ is as follows:

$$
\begin{aligned}
& B_{1}+B_{2}=\left(a_{1}+a_{2}, b_{1}+b_{2}, c_{1}+c_{2}\right) \\
& B_{1}-B_{2}=\left(a_{1}-a_{2}, b_{1}-b_{2}, c_{1}-c_{2}\right) \\
& B_{1} \otimes B_{2}=\left(a_{1} a_{2}, b_{1} b_{2}, c_{1} c_{2}\right) \\
& \lambda B_{1}=\left(\lambda a_{1}, \lambda b_{1}, \lambda c_{1}\right)
\end{aligned}
$$

As in the decision-making system, people usually make decisions according to fuzzy models using crisp values. Thus it needs to transfer fuzzy numbers into crisp values. Just right, Chen and Hwang (1992) mention a defuzzification method, which could convert fuzzy numbers into crisp scores. A good defuzzification method considers the shape, spread, height, and relative location on the $x$-axis of triangular fuzzy numbers, and regards these as significant characteristics of fuzzy numbers (Opricovic and Tzeng, 2003). There are plenty of defuzzification methods, like Centroid (Center-of-gravity) method (Yager and Filev, 1994), Chen and Hwang method, CFCS (Converting the Fuzzy data into Crisp Scores) method, and so on. Centroid method is the most commonly used defuzzification method, which provides a crisp value based on the center of gravity of the fuzzy set. However, this method can not distinguish a fuzzy number from another fuzzy number with different shape, which may lead to the two fuzzy numbers having the same crisp value. This essay adopts CFCS method for the fuzzy aggregation procedure, because the CFCS method can acquire a better crisp value.

The CFCS defuzzification method is proposed by Opricovic and Tzeng, which is based on the procedure of determining the left and right score by fuzzy minimum and fuzzy maximum from evaluation experts, and the total score is calculated in a weighted average way according to the membership functions (Opricovic and Tzeng, 2003). Suppose $\quad \tilde{A}_{i j}^{k}=\left(l_{i j}^{k}, m_{i j}^{k}, r_{i j}^{k}\right) \quad$ (where $\quad 0 \leq l \leq m \leq r \quad$ and $1 \leq k \leq K$ ) as the degree to which factor $i$ affects factor $j$ from expert $k$ 's fuzzy assessment. The fuzzy aggregation procedure contains five steps presented as follows according to the CFCS defuzzification method.

Step 1: Normalization:

$x l_{i j}^{k}=\left(l_{i j}^{k}-\min _{1 \leq k \leq K} l_{i j}^{k}\right) / \Delta_{\min }^{\max }$, 
Table 2. Corresponding relationship between linguistic variable and fuzzy number.

\begin{tabular}{lc}
\hline Linguistic variable & Corresponding triangular fuzzy number \\
\hline No influence & $(0,0,0.25)$ \\
Very low influence & $(0,0.25,0.50)$ \\
Low influence & $(0.25,0.50,0.75)$ \\
High influence & $(0.50,0.75,1.00)$ \\
Very High influence & $(0.75,1.00,1.00)$ \\
\hline
\end{tabular}

$x m_{i j}^{k}=\left(m_{i j}^{k}-\min _{1 \leq k \leq K} l_{i j}^{k}\right) / \Delta_{\min }^{\max }$,

$x r_{i j}^{k}=\left(r_{i j}^{k}-\min _{1 \leq k \leq K} l_{i j}^{k}\right) / \Delta_{\min }^{\max }$,

where $\Delta_{\min }^{\max }=\max r_{i j}^{k}-\min l_{i j}^{k}$.

Step 2: Calculate left ( $l s)$ and right $(r s)$ normalized value:

$$
\begin{aligned}
& x l s_{i j}^{k}=x m_{i j}^{k} /\left(1+x m_{i j}^{k}-x l_{i j}^{k}\right) \\
& x r s_{i j}^{k}=x r_{i j}^{k} /\left(1+x r_{i j}^{k}-x m_{i j}^{k}\right)
\end{aligned}
$$

Step 3: Compute total normalized crisp value:

$$
x_{i j}^{k}=\left[x l s_{i j}^{k}\left(1-x l s_{i j}^{k}\right)+x r s_{i j}^{k} x r s_{i j}^{k}\right] /\left(1-x l s_{i j}^{k}+x r s_{i j}^{k}\right)
$$

Step 4: Compute crisp values of expert $k$ :

$$
A_{i j}^{k}=\min l_{i j}^{k}+x_{i j}^{k} \Delta_{\min }^{\max }
$$

Step 5: Integrate crisp values:

$$
A_{i j}=\sum_{k=1}^{K} A_{i j}^{k} / K
$$

\section{ANALYZING KEY INFLUENCE FACTORS OF CITY LOGISTICS}

\section{Application of proposed method}

As a complex system, city logistics are influenced by many factors. In order to recognize the interaction between factors, this paper applies fuzzy DEMATEL method to identify critical influence factors of the system, whose procedures are stated as follows, combining with process of DEMATEL method and fuzzy logic theory.

Step 1: Determine the objective of analysis for systematic factors and establish an expert committee. The explicit goal of systematic analysis is so important that it will help you to choose an appropriate method of analysis. The target of this essay is to identify key influence factors of city logistics system. With respect to this target, this paper adopts fuzzy DEMATEL method to classify factors into cause group and effect group, so as to find out key factors. Besides, experts' judgment and assessment are indispensable in this process. So a good experts group is also essential to achieve a correct analysis results. In this paper, a committee of ten experts is formed.

Step 2: Set up the influence factors system and linguistic scale, then acquire interrelationship assessment between factors from experts. City logistics system is influenced by lots of factors and it is necessary to build the factor system from a large number of literature reviews. Most of 21 factors in this essay are from literature reviews. In order to perfect the factor system further, factors that could evaluate city logistics service level are added. Table 1 shows specific factor system, which are expressed by $S=\left\{s_{1}, s_{2}, \cdots, s_{21}\right\}$. Then the linguistic evaluation standard is needed. This essay uses fuzzy linguistic scale proposed by Li (1999), and detailed linguistic variables are presented in Table 2. Finally, a survey is carried out to investigate the mutual effect of pair-wise factors in the committee of experts.

Step 3: Translate linguistic assessments into triangular fuzzy numbers and acquire the initial direct-relation matrix. According to corresponding relationship in Table 2, linguistic assessments from 10 experts could be translated into triangular fuzzy numbers respectively. After that, summarizes all the triangular fuzzy numbers and adopts the CFCS defuzzification method through Equations 5 to 12 to obtain the initial direct-relation matrix $X=\left(x_{i j}\right)_{21 \times 21}$ ( Table 3).

Step 4: Normalize the initial direct-relation matrix and construct the total-relation matrix. Due to the different dimensions of factors in the initial direct-relation matrix, it might be difficult to compare interaction between two different pairs. So it needs to standardize the direct-relation matrix. The normalized initial direct-relation matrix $M$ is acquired through Equation 1. And then according to Equation 2, we can get the total-relation matrix $T=\left(t_{i j}\right)_{21 \times 21}($ Table 4$)$. 
Table 3. The initial direct-relation matrix $X$.

\begin{tabular}{|c|c|c|c|c|c|c|c|c|c|c|c|c|c|c|c|c|c|c|c|c|c|}
\hline & S1 & $\mathrm{S} 2$ & S3 & S4 & S5 & S6 & S7 & S8 & S9 & S10 & S11 & S12 & $\mathrm{S} 13$ & S14 & S15 & S16 & S17 & 18 & & & \\
\hline S1 & 0.000 & & & & & & & & & & & & & & & & & & & & \\
\hline S2 & & & & & & & & & & & & & & & & & & & & & \\
\hline S3 & & & & & & & & & & & & & & & & & & & & & \\
\hline$S$ & & & & & & & & & & & & & & & & & & & & & \\
\hline S5 & & & & & & & & & & & & & & & & & & & & & \\
\hline S6 & & & & & & & & & & & & & & & & & & & & & \\
\hline S7 & & & & & & & & & & & & & & & & & & & & & \\
\hline S8 & & & & & & & & & & & & & & & & & & & & & \\
\hline S9 & & & & & & & & & & & & & & & & & & & & & \\
\hline $\mathrm{S} 1$ & 117 & & & & & & & & & & & & & & & & & & & & \\
\hline & 563 & 53 & 60 & & & & & & & & & & & & & & & & & & 617 \\
\hline & & & & & & & & & & & & & & & & & & & & & \\
\hline & & & & & & & & & & & & & & & & & & & & & \\
\hline & & & & & & & & & & & & & & & & & & & & & \\
\hline & & & & & & & & & & & & & & & & & & & & & \\
\hline & & & & & & & & & & & & & & & & & & & & & \\
\hline & & & & & & & & & & & & & & & & & & & & & \\
\hline & & & & & & & & & & & & & & & & & & & & & \\
\hline & & & & & & & & & & & & & & & & & & & & & \\
\hline St & & & & & & & & & & & & & & & & & & & & & 0.593 \\
\hline $\mathrm{S} 21$ & 0.640 & 0.547 & 0.523 & 0.477 & 0.547 & 0.430 & 0.547 & 0.383 & 0.263 & 0.453 & 0.523 & 0.360 & 0.218 & 0.383 & 0.360 & 0.240 & 0.640 & 0.500 & 0.617 & 0.640 & 0.000 \\
\hline
\end{tabular}

Step 5: Draw the cause-effect relationship diagram. Calculate the sum of rows $\left(R_{i}\right)$ and sum of columns $\left(C_{i}\right)$ of matrix $T$ on the basis of Equations 3 and 4 . Then draw the cause-effect relationship diagram (Figure 1) through the dataset of $\left(R_{i}+C_{i}, R_{i}-C_{i}\right)$ and obtain structural relationship of factors. As seen in Table 5, the values of $R_{i}, C_{i}, R_{i}+C_{i}$ and $R_{i}-C_{i}$ of each factor are listed out. Taking into account each factor's values of $R_{i}, C_{i}, R_{i}+C_{i}$ and $R_{i}-C_{i}$, and combining with visualized diagram, it is easy to find out which factors have more impact on city logistics system and which factors could be improved by others. Thereby, key influence factors could be identified, which should be taken seriously in order to improve the system gradually. Using as the symbol for city logistics influence factors: transport route networks (S1), use of train or underground system (S2), use of ship terminals (S3), logistics centers (S4), hub for air freight (S5), human resources (S6), information and communications infrastructure (S7), fuel consumed (S8), pollutant emissions (S9), freight-vehicle related accidents (S10), traffic congestion (S11), road pricing (S12), load factor controls (S13), access time windows (S14), access according to weight and volume (S15), noise regulations (S16), on-time deliveries (S17), logistics cost (S18), the rate of goods defect (S19), customer satisfaction (S20) and the reliability of transportation (S21) (Figure 1).

\section{Key influence factors analysis}

In the front part, each factor's values of $R_{i}, C_{i}, R_{i}+C_{i}$ and $R_{i}-C_{i}$ are computed, and all factors are divided into cause group and effect group in Figure 1. Now in this area, 
Table 4. The total-relation matrix $T$.

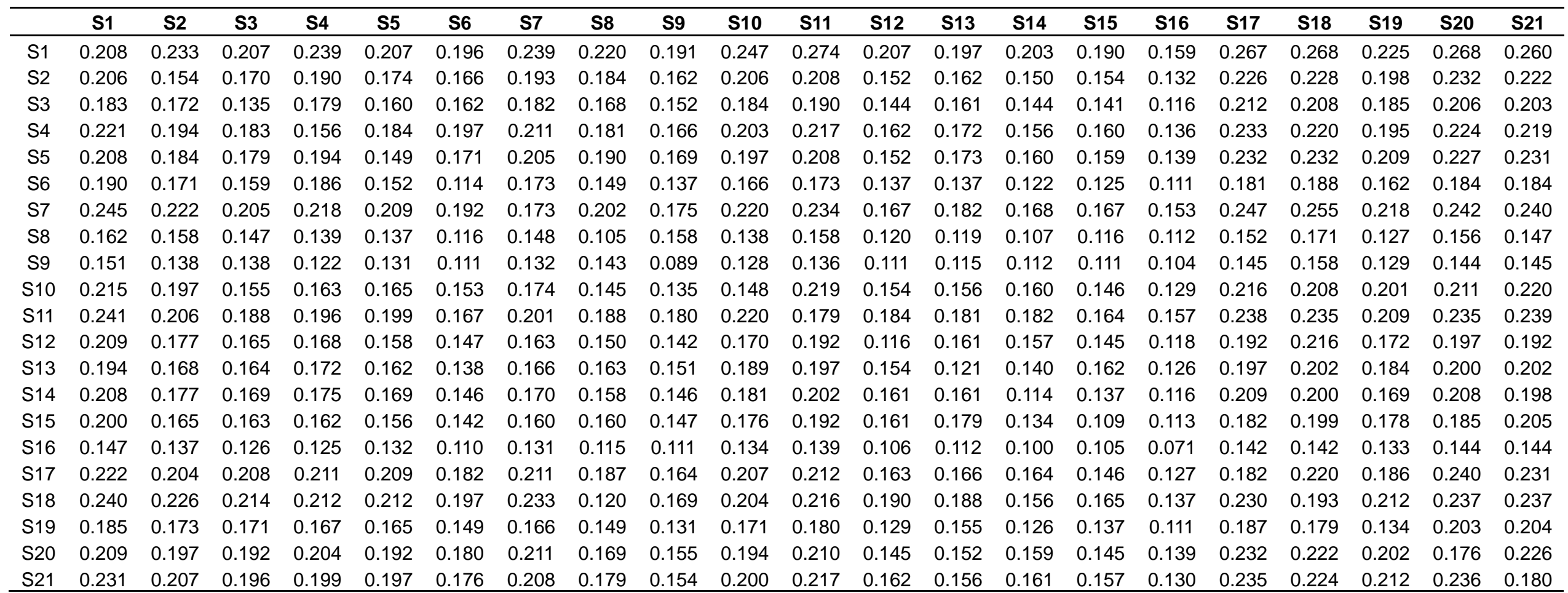

considering these scores and combining with the cause-effect relationship diagram, each systematic factor is analyzed detailedly and its impact on the whole system should be paid attention. After that, key factors of city logistics system can be figured out according to the degree of each factor's importance in the whole system and each factor's influence on others.

\section{Cause factors analysis}

As seen in Figure 1, there are ten cause factors, which are "transport route networks" (S1), "use of train or underground system" (S2), "logistics centers" (S4), "hub for air freight" (S5), "information and communications infrastructure" (S7), "traffic congestion" (S11), "road pricing" (S12), "load factor controls" (S13), "access time windows" (S14), and "access according to weight and volume" (S15). Because these factors have net effect on the system, their improvement could promote the amelioration of effect factors and the performance of the entire system. Therefore, people should pay more attention to these factors. However, some researchers treat all these cause factors as key factors directly. In this essay, instead of analyzing the cause factors one by one and identifying whether or not it plays a critical role in the whole system, eventually five key factors are figured out.

The highest value of $R_{i}-C_{i}$ among all cause factors is "access time windows" (S14). Namely, S14 has most impact on the system, but it gets less impact from other factors. Just from this point, S14 is a very important factor. However, from Table 5, the degree of influential impact of $S 14$ is 3.5710 , which is not very high among all cause factors. Moreover, "access time windows" is a governance measure in order to control traffic condition considering the traffic flow of inner city. 


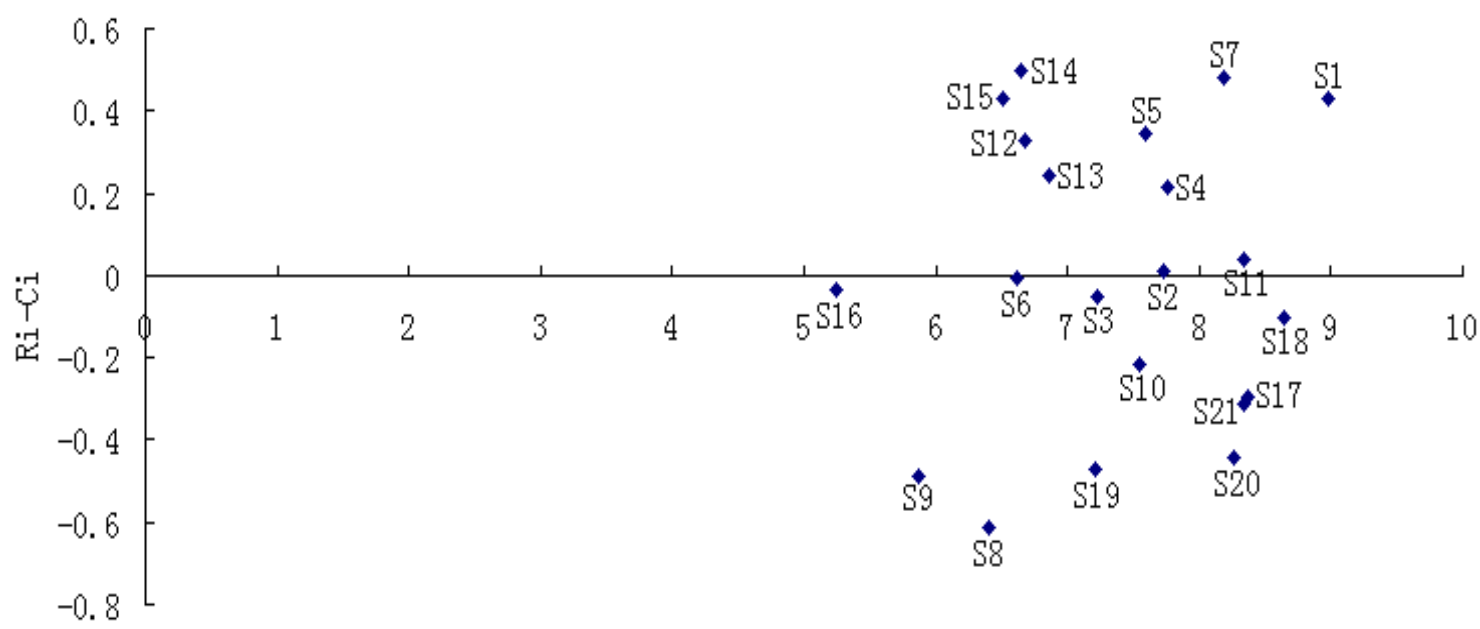

$\mathrm{Ri}+\mathrm{Ci}$

Figure 1. The cause-effect relationship diagram.

Table 5. The values of $R_{i}, C_{i}, R_{i}+C_{i}$ and $R_{i}-C_{i}$ of each factor.

\begin{tabular}{lllll}
\hline Influence criteria & $R_{i}$ & $C_{i}$ & $R_{i}+C_{i}$ & $R_{i}-C_{i}$ \\
\hline S1 transport route networks & 4.7043 & 4.2735 & 8.9778 & 0.4308 \\
S2 use of train or underground system & 3.8672 & 3.8581 & 7.7253 & 0.0091 \\
S3 use of ship terminals & 3.5850 & 3.6339 & 7.2189 & -0.0490 \\
S4 logistics centers & 3.9864 & 3.7726 & 7.7590 & 0.2137 \\
S5 hub for air freight & 3.9670 & 3.6205 & 7.5874 & 0.3465 \\
S6 human resources & 3.3010 & 3.3087 & 6.6098 & -0.0077 \\
S7 information and communications infrastructure & 4.3322 & 3.8491 & 8.1813 & 0.4831 \\
S8 fuel consumed & 2.8942 & 3.5047 & 6.3989 & -0.6106 \\
S9 pollutant emissions & 2.6931 & 3.1832 & 5.8763 & -0.4901 \\
S10 freight-vehicle related accidents & 3.6682 & 3.8815 & 7.5497 & -0.2134 \\
S11 traffic congestion & 4.1887 & 4.1513 & 8.3400 & 0.0373 \\
S12 road pricing & 3.5061 & 3.1769 & 6.6830 & 0.3292 \\
S13 load factor controls & 3.5504 & 3.3055 & 6.8559 & 0.2449 \\
S14 access time windows & 3.5710 & 3.0747 & 6.6457 & 0.4964 \\
S15 access according to weight and volume & 3.4662 & 3.0389 & 6.5051 & 0.4273 \\
S16 noise regulations & 2.6035 & 2.6356 & 5.2391 & -0.0321 \\
S17 on-time deliveries & 4.0408 & 4.3342 & 8.3750 & -0.2934 \\
S18 logistics cost & 4.2681 & 4.3683 & 8.6364 & -0.1003 \\
S19 the rate of goods defect & 3.3695 & 3.8388 & 7.2083 & -0.4692 \\
S20 customer satisfaction & 3.9112 & 4.3522 & 8.2634 & -0.4401 \\
S21 the reliability of transportation & 4.0157 & 4.3274 & 8.3431 & -0.3118 \\
\hline
\end{tabular}

During the rush hour, like the morning business hours and another peak in the afternoon, the government could limit access of freight cars to ensure people going to work on time. From this perspective, it may be easier to implement according to human's work time. Hence, S14 is not a key factor. "Information and communications infrastructure" (S7) has the second highest ${ }_{R_{i}}-C_{i}$. Its degree of influential impact is 4.3322 , which arranges second place in all cause factors. Moreover, as seen in Table 5, S7's degree of importance is 8.1813, which is not the highest but higher than others. As seen from the result of DEMATEL method, S7 is a critical factor of city logistics system. From a practical point, information and communications technology not only improves the effectiveness and 
efficiency of city logistics, but also reduces negative externalities. "Information and communications infrastructure" affects most aspects of city logistics, such as monitoring the condition of transportation, vehicle routing and scheduling, goods distribution, and so on. In a word, S7 is so important to city logistics that it is regarded as a key factor.

The net effect value $R_{i}-C_{i}$ of "transport route networks" (S1) is in the third place among all the cause factors. Meanwhile, its degree of importance and influential impact are the highest, and its degree of influenced impact is not high enough, which means S1 brings great influence to the whole system but gets little effect from others. According to the aforementioned, it is obvious that "transport route networks" is a key factor.

Though the value $R_{i}-C_{i}$ of "access according to weight and volume" (S15) is positive (the fourth place), the degree of importance, influential impact and influenced impact are low. That is to say improvement of S15 does not have enough impact on the performance of the whole system. Therefore, "access according to weight and volume" is not a key factor. As the same reason, "road pricing" (S12) and "load factor controls" (S13) can not be considered as key factors.

The score $R_{i}-C_{i}$ of "hub for air freight" (S5) is 0.3465 . Its degree of importance, influential impact and influenced impact are $7.5874,3.9670$ and 3.6205 respectively. Although these values are not the highest, it is higher than others among all cause factors. It is difficult to judge whether S5 is a key factor just from the result of DEMATEL method. In fact, "hub for air freight" plays a stimulative role in city logistics system. Usage of air freight

hub could alleviate the pressure of highway and railway transport, shorten the transport time, and then improve service level. From that view, amelioration of "hub for air freight" can promote the performance of other factors and the whole system, so S5 could be identified as a key factor.

Like "hub for air freight", with respect to "logistics centers" (S4), the scores of $R_{i}-C_{i}$ is 0.2137 , and the degree of importance, influential impact and influenced impact are not high enough. However, its practical significance can not be ignored. "Logistics centers" are one of the most crucial infrastructures in city logistics system. Its performance has great influence on the system goal, especially service level. In a certain extent, its performance also affects city environmental condition. If people do not take full advantage of logistics centers' function, it may lead to delayed goods distribution, waste of energy and cost increase and so on. According to the aforementioned analysis, S4 should be treated as a key factor.

As the externalities of city logistics, "traffic congestion" (S11) is also an important index to evaluate the development of city logistics. The value $R_{i}-C_{i}$ of $\mathrm{S} 11$ is 0.0373 , but its degree of importance, influential impact and influenced impact are high enough, which are 8.3400, 4.1887 and 4.1513 respectively. Moreover, if the problem of traffic congestion could be solved, the performance of city logistics can be improved greatly. Simultaneously, traffic congestion is an urgent problem to be settled in order to implement the strategy for sustainable development of city logistics. For this reason, S11 can be identified as a key factor.

The last cause factor is "use of train or underground system" (S2). Its scores of $R_{i}-C_{i}, R_{i}+C_{i}, R_{i}$ and $C_{i}$ are $0.0091,7.7253,3.8672$ and 3.8581 respectively. As seen from these scores, though S2 has a certain impact on the system, this impact is not very great. It does not have enough ability to ameliorate the system and can not be regarded as a key factor.

\section{Effect factors analysis}

The effect group has eleven factors from Figure 1, which are "human resources" (S6), "noise regulations" (S16), "use of ship terminals" (S3), "logistics cost" (S18), "freight-vehicle related accidents" (S10), "on-time deliveries" (S17), "the reliability of transportation" (S21), "customer satisfaction" (S20), "the rate of goods defect" (S19), "pollutant emissions" (S9) and "fuel consumed" (S8). These factors mainly reflect environmental effect and logistics service level. Generally speaking, effect factors get more impact from others. That is to say other factors' change could improve their performance, which makes them impossible to be key factors. However, special circumstances still exist. In this article, one effect factor is identified as a key factor after detailed analysis as follows.

The value $R_{i}-C_{i}$ of "human resources" (S6) is -0.0077 next to zero, which indicates its impact on the whole system less than the influence received. Its degree of importance, influential impact and influenced impact are not very high. From the aforementioned analysis result, adjustment of "human resources" can not achieve the purpose of improving the performance of the whole system. Besides, logistics operation becomes increasingly automatical, which gradually reduces its dependence on human. Hence, S6 is not a key factor. Likewise, the scores of "noise regulations" (S16), "use of ship terminals" (S3) and "freight-vehicle related accidents" (S10) have similar feature of "human resources". In addition, these three factors could be realized through the change of other factors. Thus S16, S3 and S10 are not key factors for the same reason.

As for "logistics cost" (S18), its scores of $R_{i}-C_{i}$ is -0.1003 , which means $S 18$ is a net effect factor and it receives more impact from others than it dispatches. From Table 5, S18's value of $C_{i}$ is 4.3683 , which implies the highest influenced impact, but it has the second highest 
score of $R_{i}+C_{i}$ and the third highest value of $R_{i}$. Namely, although "logistics cost" is an effect factor, it plays a prominent role in city logistics system, and it also has significant impact on other factors. Furthermore, logistics cost is a very important index to evaluate the performance of city logistics. City logistics can develop better only providing a higher logistics service level with lower cost. So S18 is considered as a key factor.

Concerning "on-time deliveries" (S17), "the reliability of transportation" (S21) and "customer satisfaction" (S20), they have some similar characteristics, Namely, their scores of $R_{i}+C_{i}, R_{i}$ and $C_{i}$ are very high, but the scores of $R_{i}-C_{i}$ are below zero. Taking $\mathrm{S} 17$ as an example, the degree of importance and influenced impact of $S 17$ are 8.3750 and 4.3342 , which rank the third place among all factors, but the degree of influential impact is 4.0408 not high enough. As the representatives of the service level, this means that though they exert a considerable impact on city logistics system, their improvement is easily achieved by the change of other factors. Therefore, these three factors can not be labeled as key factors.

The remaining effect factors are "the rate of goods defect" (S19), "pollutant emissions" (S9) and "fuel consumed" (S8), which are all net effect factors. And their degree of importance are not very high, especially the degree of S9 ranking the twentieth place. Their degrees of influential impact are lower than others. Furthermore, their influenced impact is higher than influential impact, which implies they are susceptible to others. Consequently, the modification of others can greatly improve their performance, and they do not play a critical role in the whole system. So S19, S9 and S8 can not be regarded as key factors.

\section{KEY FACTORS DISCUSSION}

In this paper, six key factors are identified, which are "information and communications infrastructure" (S7), "transport route networks" (S1), "hub for air freight" (S5), "logistics centers" (S4), "traffic congestion" (S11), "logistics cost" (S18). These six factors reflect three aspects of city logistics - infrastructure, environmental effects and service level. Obviously, four in six factors belong to logistics infrastructure, which are "information and communications infrastructure" (S7), "transport route networks" (S1), "hub for air freight" (S5) and "logistics centers" (S4). That is to say infrastructure plays a decisive role in city logistics system. Of course, developing city logistics can not ignore its negative impact and service level. Six key factors are stated detailedly as follows.

"Information and communications infrastructure" (S7) is a foundation of information system, which influences all aspects of city logistics system. A good information foundation can not only improve the efficiency of city logistics, but also alleviate externalities of city logistics. For example, applying global positioning system (GPS) navigation system to freight vehicles can improve transportation efficiency, and also save the time to find the right path, reduce pollutant emission and energy consumption. The application of this technology not only improves logistics service, but also reduces the negative impact of city logistics. Another typical example is application of intelligent transportation system (ITS). On the one hand, ITS could improve transportation safety and reduce energy consumption. On the other hand, ITS enhances the capacity of road networks, which reduces traffic congestion in a certain degree. As seen from these examples, information and communications infrastructure plays a critical role in development of city logistics. Therefore, it is necessary to improve information and communications infrastructure gradually to promote the development of city logistics.

It is easy to imagine the importance of "transport route networks" (S1). Whether road or rail transportation, a weak transport network may lead to an inefficient transport system. This not only affects the level of city logistics service, but increases the negative impact on environment, such as the weak transport network boosts energy consumption, emission of freight vehicles, and traffic congestion. As the main mode of transportation in city logistics system, highway transport largely depends on fluent road networks. Fluent transport route networks can well reflect the convenience and flexibility of highway transport. At the same time, good transport network can make full use of rail transportation's function in city logistics system, and it can ease the pressure of highway transportation and traffic congestion. Thus a good transport route network is a key foundation of steady development of city logistics.

The main influence of "hub for air freight" (S5) is service level of city logistics and environmental effect. Air transport has many advantages. One is great reduction on transportation time and the rate of goods defect. Another advantage is that air transport does not suffer from the limitation of ground (for example, traffic congestion). Making full use of air freight hub can availably resolve the problem of trunk line transportation in city logistics, greatly improve the logistics operation efficiency, and relieve the pressure of highway and railway transport and traffic congestion. According to these, the amelioration of air freight hub can improve the performance of other factors and the whole city logistics system.

The operation level of "logistics centers" (S4) influences the performance and cost of city logistics. It also affects service level in another way. Transport distribution function of logistics center can improve the efficiency of transportation system, save transportation cost, and then improve operation level and service level of city logistics. The function of goods sorting, storing and packaging in logistics center has close relation with service level. So taking full advantage of logistics center can perfect city 
logistics system and enhance the service level.

"Traffic congestion" (S11) is a common problem of many cities. It is also a difficult issue to local government and residents. Although traffic congestion is the result of many factors' interaction, it is a technical problem, and also an economic issue, but also a social problem. However, the relation of city logistics and traffic congestion is so close that they can not be discussed separately. It is the representation of city logistics' externality, and its emergence has important influence on city logistics. Traffic congestion causes various harms to the whole system, such as waste of time, rise of operating cost, increase of traffic accidents, inconvenience of residents' travel, environment pollution and so on. Due to great negative effect of traffic congestion on city logistics, it is essential to control the traffic condition to ensure efficient development of city logistics.

"Logistics cost" (S18) implies not only the service level, but also logistics operation level. It is a critical index to estimate the performance of city logistics. If the logistics cost is high for the city, correspondingly logistics pricing is also high to maintain the appropriate profit space, which will seriously affect customer satisfaction and the cooperation of logistics business with other cities and worse still, finally influence the development level of city logistics. However, if the logistics cost is very low for the city, much lower than the industry average, its service quality is questioned, which is also not beneficial to develop city logistics. In order to develop city logistics steadily and efficiently, it needs to put the logistics cost in a reasonable range.

\section{CONCLUSIONS AND FUTURE STUDY}

This paper summarizes previous researches concerning influence factors of city logistics. On the basis of previous studies, the factors about service level are added according to the features of city logistics. Thus a complete index system related to city logistics influence factors is constructed from four aspects, namely logistics infrastructure, environmental effects, governance measures and logistics service level. With respect to this index system, the fuzzy DEMATEL method is applied to analyze all influence factors one by one so as to identify the key influence factors. According to the results of fuzzy DEMATEL method, six key factors are figured out, which are "information and communications infrastructure" (S7), "transport route networks" (S1), "hub for air freight" (S5), "logistics centers" (S4), "traffic congestion" (S11), "logistics cost" (S18). With the gradual improvement of these factors in the city logistics operation, the development level of city logistics might be increased.

This paper pioneers in studying how to identify the key influence factors of city logistics system, but the comprehensive and feasible measure related to key influence factors has not been proposed. So as for further research, it is worth discussing how to implement these key influence factors in city logistics planning.

\section{REFERENCES}

Anderson S, Allen J, Browne M (2005). Urban logistics-how can it meet policy makers' sustainability objectives. J. Transp. Geogr. 13:71-81.

BESTUFS (2007). BESTUFS-Good practice guide on urban freight. BESTUFS Consortium, www.bestufs.net.

Busse C (2010). A procedure for second data analysis: innovation by logistics service providers. J. Supply Chain Manage. 46:44-58.

Chen SJ, Hwang CL (1992). Fuzzy multiple attribute decision making: methods and applications. Berlin: Springer-Verlag.

Chang B, Chang CW, Wu CH (2011). Fuzzy DEMATEL method for developing supplier selection criteria. Exp. Syst. Appl. 38:1850-1858.

Eduardo BQ, Romero JA (2010). An urban freight transport index. Procedia Soc. Behav. Sci. 2:6312-6322.

Fontela E, Gabus A (1976). The DEMATEL Observer, DEMATEL 1976 Report. Switzerland Geneva: Battelle Geneva Research Center.

Figliozzi MA (2011). The impacts of congestion on time-definitive urban freight distribution networks $\mathrm{CO}_{2}$ emission level: Results from a case study in Portland, Oregon. Transp. Res. Part C. 19:766-778.

Gabus A, Fontela E (1973). Perceptions of the world problematique: Communication procedure, communicating with those bearing collective Responsibility (DEMATEL). Switzerland Geneva: Battelle Geneva Research Center. P.1

Karsak EE, Tolga E (2001). Fuzzy multi-criteria decision-making procedure for evaluating advanced manufacturing system investments. Int. J. Prod. Econ. 69:49-64.

Kuse H, Endo A, Iwao E (2010). Logistics facility, road network and district planning: establishing comprehensive planning for city logistics. Proced. Soc. Behav. Sci. 2:6251-6263.

Li RJ (1999). Fuzzy method in group decision making. Comput. Math. Appl. 38:91-101.

Munuzuri J, Larraneta J, Onieva L, Cortes P (2005). Solutions applicable by local administrations for urban logistics improvement. Cities. 22:15-28.

Magalhaes DJ (2010). Urban freight transport in a metropolitan context: the Belo Horizonte city case study. Procedia Soc. Behav. Sci. 2:6076-6086.

Opricovic S, Tzeng GH (2003). Defuzzification within a multicriteria decision model. Int. J. Uncertain. Fuzziness. Knowl-based Syst. 11: 635-652.

Petersen T (2006). Development of a city logistics concept. Prod. Plann. Control. 17:616-623.

Russo F, Comi A (2010). A classification of city logistics measures and connected impacts. Procedia Soc. Behav. Sci. 2:6355-6365.

Seyed-Hosseini SM, Safaei N, Asgharpour MJ (2006). Reprioritization of failures in a system failure mode and effects analysis by decision making trial and evaluation laboratory technique. Reliab. Eng. Syst. Saf. 91:872-881.

Sheu JB (2006). A novel dynamic resource allocation model for demand-responsive city logistics distribution operations. Transp. Res. Part E. 42:445-472.

Shao JP, Ma TY, Dong SH, Meng XH (2009). Evaluation and analysis: development trend of China's logistics industry under supply chain globalization environments. J. Service Sci. Manage. 2:71-79.

Taniguchi E, Thompson RG, Yamada T (1999). Modeling city logistics. In E. Taniguchi \& R. G. Thompson (Eds.), City logistics (3-37). Kyoto: Institute of Systems Science Research.

Taniguchi E (2000). An evaluation methodology for city logistics. Transp. Rev. 20(1):65-90.

Taniguchi E (2001). City logistics. Infrastructure Plann. Rev. 18:1-16.

Taniguchi E, Thompson RG, Yamada T (2003). Predicting the effects of city logistics schemes. Transp. Rev. 23:489-515.

Taniguchi E, Tamagawa D (2005). Evaluating city logistics measures considering the behavior of several stakeholders. J. Eastern Asia Soc. Transp. Stud. 6:3062-3076.

Tzeng GH, Chiang CH, Li CW (2007). Evaluating intertwined effects in e-learning program: A novel hybrid MCDM model based on factor analysis and DEMATEL. Exp. Syst. Appl. 32:1028-1044.

Taniguchi E, Thompson RG, Yamada T (2010). Incorporating risks in 
city logistics. Procedia Soc. Behav. Sci. 2:5899-5910.

Tamagawa D, Taniguchi E, Yamada T (2010). Evaluating city logistics measures using a multi-agent model. Procedia Soc. Behav. Sci. 2:6002-6012.

Wu WW, Lee YT (2007). Developing global managers' competencies using the fuzzy DEMATEL method. Exp. Syst. Appl. 32:499-507.

Woudsma C, Jensen JF, Kanaroglou P, Maoh H (2008). Logistics land use and the city: A spatial-temporal modeling approach. Transp. Res. Part E. 44:277-297.

Yager RR, Filev DP (1994). Essentials of fuzzy modeling and control. New York: John Wiley \& Sons, inc.

Zadeh LA (1965). Fuzzy sets. Infor. Control. 8:338-353.

Zadeh LA (1973). Outline of a new approach to the analysis of complex system and decision processes. IEEE Transactions On Systems, Man and Cybernetics. 3:28-44.

Zadeh LA (1975). The concept of a linguistic variable and its application to approximate reasoning. Infor. Sci. 8(i):199-249 and (ii):301-357. Zimmermann HJ (1991). Fuzzy set theory and its applications. (2nd ed.). Kluwer Academic Publisher.

Zhou Q, Huang WL, Zhang Y (2011). Identifying critical success factors in emergency management using a fuzzy DEMATEL method. Saf. Sci. 49:243-252. 